\title{
Optimal Economic-Environmental Operation of BESS in AC Distribution Systems: A Convex Multi-Objective Formulation
}

\author{
Walter Gil-González ${ }^{1}\left(\mathbb{D}\right.$, Oscar Danilo Montoya ${ }^{2,3, *(\mathbb{C}}$, Luis Fernando Grisales-Noreña ${ }^{4}$ (D) \\ and Andrés Escobar-Mejía 5 (D) \\ 1 Facultad de Ingeniería, Institución Universitaria Pascual Bravo, Campus Robledo, \\ Medellín 050036, Colombia; walter.gil@pascualbravo.edu.co \\ 2 Facultad de Ingeniería, Universidad Distrital Francisco José de Caldas, Bogotá 110231, Colombia \\ 3 Laboratorio Inteligente de Energía, Universidad Tecnológica de Bolívar, Cartagena 131001, Colombia \\ 4 Department of Electromechanical and Mechatronic, Faculty of Engineering, Instituto Tecnológico \\ Metropolitano, Robledo Campus, Medellín 050036, Colombia; luisgrisales@itm.edu.co \\ 5 Facultad de Ingenierías, Universidad Tecnológica de Pereira, Pereira 660003, Colombia; andreses1@utp.edu.co \\ * Correspondence: odmontoyag@udistrital.edu.co
}

check for

updates

Citation: Gil-González, W.; Montoya, O.D.; Grisales-Noreña, L.F.; Escobar-

Mejía, A. Optimal Economic-

Environmental Operation of BESS in AC Distribution Systems: A Convex Multi-Objective Formulation.

Computation 2021, 9, 137. https://

doi.org/10.3390/computation9120137

Academic Editor: Demos T. Tsahalis

Received: 2 November 2021

Accepted: 3 December 2021

Published: 10 December 2021

Publisher's Note: MDPI stays neutral with regard to jurisdictional claims in published maps and institutional affiliations.

Copyright: (C) 2021 by the authors. Licensee MDPI, Basel, Switzerland. This article is an open access article distributed under the terms and conditions of the Creative Commons Attribution (CC BY) license (https:// creativecommons.org/licenses/by/ $4.0 /)$.

\begin{abstract}
This paper deals with the multi-objective operation of battery energy storage systems (BESS) in AC distribution systems using a convex reformulation. The objective functions are $\mathrm{CO}_{2}$ emissions, and the costs of the daily energy losses are considered. The conventional non-linear nonconvex branch multi-period optimal power flow model is reformulated with a second-order cone programming (SOCP) model, which ensures finding the global optimum for each point present in the Pareto front. The weighting factors methodology is used to convert the multi-objective model into a convex single-objective model, which allows for finding the optimal Pareto front using an iterative search. Two operational scenarios regarding BESS are considered: (i) a unity power factor operation and (ii) a variable power factor operation. The numerical results demonstrate that including the reactive power capabilities in BESS reduces $200 \mathrm{~kg}$ of $\mathrm{CO}_{2}$ emissions and USD 80 per day of operation. All of the numerical validations were developed in MATLAB 2020b with the CVX tool and the SEDUMI and SDPT3 solvers.
\end{abstract}

Keywords: battery energy storage system; multi-objective optimization model; distribution networks; non-linear optimization; convex reformulation; second-order cone programming

\section{Introduction}

Energy storage systems play a key role in technological and industrial development, with applications in the smartphone, computers, conventional and electric vehicles, distribution networks, and renewable electricity generation [1-3], among others. In general, these energy storage systems are based on chemical technologies; most commonly leadacid [4], nickel-cadmium [5], and lithium-ion [6,7] batteries. In electrical grids, battery energy storage systems (BESS) are widely used for power and energy compensation [8], power oscillation damping [9], frequency generation, and voltage support [10]. One of the fundamental applications of BESS is the use of energy from renewable sources to reduce the operating costs of electrical grids and to mitigate greenhouse gas emissions [11,12].

Including BESS in electricity distribution networks is a complex task in terms of control and optimization. For control, efficient energy management strategies must be designed considering non-linear characteristics of the converters that interface them with the electrical grid, which requires applying non-linear control methods for an adequate operation of BESS and their local and or global dynamic stability [13,14]. Some of the control methods that are applied to BESS systems include sliding mode control [15], passivity-based control [16], exact feedback linearization [17], fuzzy logic [18,19], neural networks [20], and classic proportional-integral-derivative (PID) controllers [21], among others. For 
optimization, a major challenge to overcome with BESS is the economic and environmental dispatch, which is a non-linear and nonconvex optimization problem with a difficult solution. Generally, this problem requires determining BESS charging/discharging periods taking advantage of available renewable sources during a defined period of operation (typically $24 \mathrm{~h}$ ) in order to reduce one or more objective functions. The main complicating factor of this problem is the presence of power balance equations in each node of the system, because these equations are non-linear and typically require numerical solution methods.

In line with the above, the authors of [22] proposed a non-linear programming model for operating batteries on alternating current $(\mathrm{AC})$ electrical grids with a power factor of 1.0. This model was solved in a general algebraic modeling system (GAMS). An improvement of this model was proposed in [8], which considers the possibility of injecting reactive power; however, it was solved using GAMS software, which, given the non-linear nature of the problem, does not necessarily lead to the global optimum. The authors [23] proposed a solution technique for the battery location and operative problem in distribution networks using a genetic algorithm combined with a particle swarm algorithm. In this model, BESS was run with a unity power factor, and their power injection was modeled with binary variables, complicating their solution. The authors [11] presented a mixedinteger non-linear programming model to determine the battery location and size in AC networks, considering unity and variable power factors. The solution to this mathematical model was found in the GAMS software. Given the non-linear and nonconvex nature of the problem, the global optimum is not necessarily found. The authors [24] proposed a reformulation of the second-order cone programming model to operate batteries in AC networks, which guarantees finding the global optimum; however, the reformulation of the problem is based on a single-objective equivalent, combining greenhouse gas emissions with the cost of energy losses, which prevents a Pareto optimal front. The authors of [25] proposed a semidefinite programming (SDP) model for solving the problem of volt/VAR optimization in unbalanced distribution grids with BESS to minimize power loss. However, the problem of the SDP model lies in recovering the rank-one solution from the matrix, which complicates it at the time of a real application. The authors of [26] presented a methodology based on the equilibrium optimization algorithm for the optimal integration of photovoltaic (PV) with BESS in order to improve the distribution network performance. The authors of [27] showed an improved sunflower optimization algorithm for optimal capacitor banks re-allocation in smart distribution networks. The authors of [28] performed a methodology using the coyote optimization algorithm to reduce the losses in the electricity distribution network by employing the BESS. Other studies have proposed optimization models for series-parallel configurations of battery cells to balance their thermodynamic performance [29]; however, these models overlook the distribution network in their formulation and primarily focus on electric vehicle applications [21]. Additionally, it is also important to determine the parameters adequately for the BESS in order to apply some methods mentioned above; the authors of [30] described an enhanced procedure to estimate the BESS parameters using an equilibrium optimization algorithm. Unlike previous studies, this article contributes the following:

$\checkmark \quad$ A multi-purpose convex formulation for the efficient operation of energy storage systems in alternating current distribution networks, considering the simultaneous minimization of carbon dioxide emissions in diesel plants and energy losses in conductors. To this end, a reformulation of the second-order cone programming model of the multi-period optimal flow problem is proposed, with the main advantage of ensuring that the global optimum is found;

$\checkmark \quad$ The application of the weighted weights method to transform the multi-objective optimization model into a single-objective equivalent, which is iteratively solved to obtain the Pareto optimal front by solving this model using the Self-Dual-Minimization (SeDuMi) and SemiDefinite Programming (SDPT3) tools available in the MATLAB CVX tool; 
$\checkmark \quad$ The assessment of the effect of manageable reactive power injection in the batteries concerning the cost of $\mathrm{CO}_{2}$ losses and emissions when compared with the unity power factor scenario.

The remainder of this document is organized as follows: In Section 2, the formulation of the multi-objective operation problem of BESS in distribution systems is presented, highlighting their non-linear and nonconvex characteristics given by power balance equations and by voltage drops in branches. In Section 3, a convex reformulation is proposed by transforming the original non-linear model into a second-order cone programming model. Section 4 briefly describes the solution method; this method combines objective functions using weighted weights. In Section 5, the main characteristics of the radial IEEE 33-node test system are presented, composed of a slack node, four distributed generators, and three batteries. In Section 6, the computational validation is presented, considering two operational scenarios for BESS, based on unity and variable power factors. In Section 7, the main conclusions of this study are presented, as well as future perspectives.

\section{Mathematical Formulation}

The problem of the optimal operation of battery energy storage systems in distribution networks is formulated as a multi-objective optimization problem in which mitigating the emissions of greenhouse gases $\left(\mathrm{CO}_{2}\right.$ emissions) and reducing the cost of energy losses during the operating period are the objective functions. The structure of these objective functions is presented below:

$$
\begin{array}{r}
\min f_{1}=C O_{2}^{\mathrm{em}} \sum_{t \in \mathcal{T}} \sum_{i \in \mathcal{N}} p_{0 i, t} \Delta t, \\
\min f_{2}=C_{\text {ave }}^{\text {energy }} \sum_{t \in \mathcal{T}} \sum_{i j \in \mathcal{L}} R_{i j} I_{i j, t}^{2} \Delta t,
\end{array}
$$

where $f_{1}$ represents the value of the objective function associated with $\mathrm{CO}_{2}$ emissions to the atmosphere produced by diesel generators (measured in $\mathrm{CO}_{2}$ tons per day, i.e., tons/day) and $f_{2}$ is the value of the objective function related to the daily cost of energy losses in all conductors of the distribution network (measured in USD/day); $\mathrm{CO}_{2}^{\mathrm{em}}$ represents the rate of carbon dioxide emissions for medium-capacity diesel generation (i.e., $<10 \mathrm{MW}$ ); $\Delta t$ is the fraction of time associated with the study period, i.e., $30 \mathrm{~min}$ for this study; $C_{\text {ave }}^{\text {energ }}$ corresponds to the average kilowatt-hour cost of grid losses during electric power transmission; $p_{0 i, t}$ represents the amount of active power flowing from the substation node (i.e., source node 0 ) to the node $i$ in the time period $t ; R_{i j}$ corresponds to the value of the resistance between the nodes $i$ and $j ; I_{i j, t}$ corresponds to the magnitude of the current that flows between the nodes $i$ and $j$ in the time period $t$. It should be noted that $\mathcal{N}, \mathcal{L}$, and $\mathcal{T}$ correspond to the sets that contain all system nodes, all network sections, and all time periods, respectively.

The set of constraints associated with the optimal multi-objective dispatch problem of BESS contains the classic equations of active and reactive power balance and voltage drops in branches [31], as well as element capacity constraints, in addition to battery operating characteristics. The complete set of constraints of the optimization problem under study is presented below.

$$
\begin{array}{r}
p_{i j, t}-R_{i j} I_{i j, t}^{2}-\sum_{k:(j, k) \in \mathcal{L}} p_{j k, t}=P_{j, t}-p_{j, t}^{d g}-p_{j, t}^{b}\{j \in \mathcal{N}, t \in \mathcal{T}\}, \\
q_{i j}-X_{i j} I_{i j, t}^{2}-\sum_{k:(j, k) \in \mathcal{L}} q_{j k, t}=Q_{j, t}-q_{j, t}^{d g}-q_{j, t}^{b}\{j \in \mathcal{N}, t \in \mathcal{T}\}, \\
V_{j, t}^{2}=V_{i, t}^{2}-2\left(R_{i j} p_{i j, t}+X_{i j} q_{i j, t}\right)+\left(R_{i j}^{2}+X_{i j}^{2}\right) I_{i j, t}^{2}\{(i, j) \in \mathcal{L}, t \in \mathcal{T}\},
\end{array}
$$




$$
\begin{array}{r}
I_{i j, t}^{2}=\frac{p_{i j, t}^{2}+q_{i j, t}^{2}}{V_{i, t}^{2}},\{(i, j) \in \mathcal{L}, t \in \mathcal{T}\}, \\
s o c_{j, t}^{b}=s o c_{j, t-1}^{b}-\varphi_{j}^{b} p_{j, t}^{b} \Delta T,\{t \in \mathcal{T}, j \in \mathcal{N}\}, \\
\left(p_{j, t}^{b}\right)^{2}+\left(q_{j, t}^{b}\right)^{2} \leq\left(s_{j}^{b, \max }\right)^{2},\{t \in \mathcal{T}, j \in \mathcal{N}\}, \\
p_{j, t}^{b, \min } \leq p_{j, t}^{b} \leq p_{j, t}^{b, \max },\{t \in \mathcal{T}, j \in \mathcal{N}\}, \\
\operatorname{soc}_{j}^{b, \min } \leq \operatorname{soc}_{j, t}^{b} \leq s o c_{j}^{b, \max },\{t \in \mathcal{T}, j \in \mathcal{N}\}, \\
p_{j, t}^{g d, \min } \leq p_{j, t}^{g d} \leq p_{j, t}^{g d, \max },\{t \in \mathcal{T}, j \in \mathcal{N}\}, \\
\left(p_{j, t}^{g d}\right)^{2}+\left(q_{j, t}^{g d}\right)^{2} \leq\left(s_{j}^{g d, \max }\right)^{2},\{t \in \mathcal{T}, j \in \mathcal{N}\}, \\
V^{\min } \leq V_{j, t} \leq V^{\max },\{t \in \mathcal{T}, j \in \mathcal{N}\},
\end{array}
$$

where $p_{i j, t}$ and $q_{i j, t}$ represent the flows from the node $i$ to the node $j$ in the time period $t$; $p_{j k, t}$ and $q_{j k, t}$ are defined as the nodes $j$ and $k$ above, respectively; $P_{j, t}$ and $Q_{j, t}$ correspond to the active and reactive power consumptions at node $j$ in each time period $t$. These loads have been modeled as constant power loads: $p_{j, t}^{d g}$ and $q_{j, t}^{d g}$ are the active and reactive powers generated in the distributed sources connected to the node $j$ in the time period $t ; p_{j, t}^{b}$ and $q_{j, t}^{b}$ represent the active and reactive power generation or consumption in the battery $b$ connected to the node $j$ in the time period $t ; V_{i, t}$ and $V_{j, t}$ correspond to the voltage magnitudes at the nodes $i$ and $j$ in the time period $t$, respectively. $s o c_{j, t}^{b}$ represents the state of charge of the battery connected to the node $j$ in the time period $t$, with $\varphi_{j}^{b}$ being the battery charge/discharge coefficient. $s o c_{j}^{b, \min }$ and $s o c_{j}^{b, \min }$ correspond to the lower and upper bounds for the state-of-charge battery variables (these values should be higher than zero and lower than one; more specifically, for lithium-ion batteries, the values ranging from $10 \%$ to $90 \%$ are recommended, according to [8]). $p_{j, t}^{b, \min }$ and $p_{j, t}^{b, \max }$ represent the active power bounds of the batteries, $s_{j}^{b, \max }$ being the maximum power transfer/absorption bounds of the battery $b$ connected to the node $j . p_{j, t}^{g d, \min }$ and $p_{j, t}^{g d \text {,max }}$ represent the active and reactive power bounds of the renewable generation sources connected to the node $j$ in the time period $t, s_{j}^{g d, \max }$ being the maximum apparent power transfer, and $V^{\min }$ and $V^{\max }$ correspond to minima and maxima associated with voltage regulation in all nodes of the distribution network.

In the mathematical model defined from (1) to (13), Equations (3) to (6) are nonlinear and non-convex due to the presence of squared current, voltage, and power variables. However, as stated by [31], the main complication of this mathematical model is the constraint (6), which is associated with the hyperbolic relationship that exists between voltages, currents, and powers.

The mathematical model (1)-(13) that represents the multi-objective operation of energy storage systems in alternating current distribution networks is interpreted as follows: Equations (1) and (2) define the objective functions of interest, the first of which being related to the mitigation of greenhouse gas emissions associated with carbon dioxide, and the second being related to the daily cost of energy losses in conductors of the distribution network. Equations (3) and (4) define the balance between active and reactive power in each node of the system, whereas Equation (5) is related to the voltage drop in each branch of the distribution system. Equation (6) defines the non-linear relationship between voltage and current, according to Tellegen's theorem, associated with the definition of electric power; Equations (7) to (10) define, in their order, the linear relationship between the state of charge and the active power injected/imported or absorbed with the battery, the apparent power transfer capacity, and the active power injection bounds and the admissible state-of-charge bounds, respectively. Equations (11) and (12) are associated with the 
active power generation capacity of renewable generators, as well as their apparent power transfer bounds, respectively. Lastly, inequality (13) is known as the voltage regulation constraint, which is responsible for limiting the maximum voltage drop of the network, according to regulatory requirements applicable to medium voltage levels.

A key characteristic of the mathematical optimization model proposed for the problem of the efficient operation of energy storage systems in energy distribution networks is the ability to use the converter that integrates the battery as a reactive power compensation element $[32,33]$. It is worth mentioning that reactive power compensation with the battery compensator is entirely plausible because this device essentially operates as a static power compensator, whereby, based on an efficient control method, reactive power can be managed in two quadrants as a function of electrical grid requirements [34]. However, the stage of the voltage source converter control for reactive power management is beyond the scope of this article, so readers should refer to the references [8,35] for further details.

Deriving an equivalent convex mathematical model of the multi-objective problem defined from (1) to (13) only requires finding the convex equivalent of Equations (3) to (6) because the other equations, including the objective functions, are convex. The quadratic objective function associated with the power losses is convex because the resistance parameters are always higher than zero [24].

The convexification of the mathematical model (1)-(13) will be described in detail in the following section using second-order cone programming, as discussed in [31].

\section{Convex Reformulation}

To ensure that the global optimum is found in the nonlinear formulation of (1) presented by (13) for the economic-environmental dispatch problem of batteries in AC distribution systems with radial configuration, in this study, this model is transformed into an equivalent second-order cone programming model. This reformulation of the problem basically consists of transforming the nonlinear Equations (3) to (6) into equivalent planes, i.e., affine constraints. For this purpose, the following auxiliary variables are considered: $l_{i j, i}=I_{i j, t}^{2}$ and $u_{j, t}=V_{j, t}^{2}$. With these definitions, the objective function associated with energy losses (see Equation (2)), active and reactive power balance constraints, i.e., Equations (3) and (4), become linear, as does voltage drop constraints, i.e., (5). Therefore, the only complicated constraint is Equation (6) because it contains a product between variables, as shown below:

$$
p_{i j, t}^{2}+q_{i j, t}^{2}=l_{i j, t} u_{j, t},\{(i, j) \in \mathcal{L}, t \in \mathcal{T}\}
$$

This restriction can be easily transformed using the equivalent hyperbolic relation of the product of variables, as detailed below (set notation is omitted for simplicity):

$$
\begin{aligned}
l_{i j, t} u_{j, t} & =\frac{1}{4}\left(l_{i j, t}+u_{j, t}\right)^{2}-\frac{1}{4}\left(l_{i j, t}-u_{j, t}\right)^{2}, \\
p_{i j, t}^{2}+q_{i j, t}^{2} & =\frac{1}{4}\left(l_{i j, t}+u_{j, t}\right)^{2}-\frac{1}{4}\left(l_{i j, t}-u_{j, t}\right)^{2} \\
\left(l_{i j, t}+u_{j, t}\right)^{2} & =\left(2 p_{i j, t}\right)^{2}+\left(2 q_{i j, t}\right)^{2}+\left(l_{i j, t}-u_{j, t}\right)^{2}, \\
\left\|\begin{array}{c}
2 p_{i j, t} \\
2 q_{i j, t} \\
l_{i j, t}-u_{j, t}
\end{array}\right\| & =l_{i j, t}+u_{j, t},\{(i, j) \in \mathcal{L}, t \in \mathcal{T}\} .
\end{aligned}
$$

The constraint (15) remains nonconvex [24] due to the condition of equality; accordingly, to obtain a conic equivalent, this constraint is relaxed using the inequality symbol, as follows:

$$
\left\|\begin{array}{c}
2 p_{i j, t} \\
2 q_{i j, t} \\
l_{i j, t}-u_{j, t}
\end{array}\right\| \leq l_{i j, t}+u_{j, t},\{(i, j) \in \mathcal{L}, t \in \mathcal{T}\} .
$$


Note that, with Equation (16), the multi-objective mathematical model (1)-(13) becomes convex. This optimization is known as second-order cone programming (SOCP). The complete mathematical model is presented below, describing the constraints (8) and (12), as in (16), to standardize the structure of the mathematical model.

$$
\begin{aligned}
& \min f_{1}=\mathrm{CO}_{2}^{\mathrm{em}} \sum_{t \in \mathcal{T}} \sum_{i \in \mathcal{N}} p_{0 i, t}, \\
& \min f_{2}=C_{\text {ave }}^{\text {energy }} \sum_{t \in \mathcal{T}} \sum_{i j \in \mathcal{L}} R_{i j} l_{i j, t} \Delta t, \\
& p_{i j, t}-R_{i j} l_{i j, t}-\sum_{k:(j, k) \in \mathcal{L}} p_{j k, t}=P_{j, t}-p_{j, t}^{d g}-p_{j, t}^{b},\{j \in \mathcal{N}, t \in \mathcal{T}\}, \\
& q_{i j}-X_{i j} l_{i j, t}-\sum_{k:(j, k) \in \mathcal{L}} q_{j k, t}=Q_{j, t}-q_{j, t}^{d g}-q_{j, t}^{b},\{j \in \mathcal{N}, t \in \mathcal{T}\}, \\
& u_{j, t}=u_{i, t}-2\left(R_{i j} p_{i j, t}+X_{i j} q_{i j, t}\right)+\left(R_{i j}^{2}+X_{i j}^{2}\right) l_{i j, t},\{(i, j) \in \mathcal{L}, t \in \mathcal{T}\}, \\
& \left\|\begin{array}{c}
2 p_{i j, t} \\
2 q_{i j, t} \\
l_{i j, t}-u_{j, t}
\end{array}\right\| \leq l_{i j, t}+u_{j, t},\{(i, j) \in \mathcal{L}, t \in \mathcal{T}\}, \\
& \operatorname{soc}_{j, t}^{b}=\operatorname{soc}_{j, t-1}^{b}-\varphi_{j}^{b} p_{j, t}^{b} \Delta T,\{t \in \mathcal{T}, j \in \mathcal{N}\}, \\
& \left\|\begin{array}{c}
p_{j, t}^{b} \\
q_{j, t}^{b}
\end{array}\right\| \leq s_{j}^{b, \max },\{t \in \mathcal{T}, j \in \mathcal{N}\}, \\
& p_{j, t}^{b, \min } \leq p_{j, t}^{b} \leq p_{j, t}^{b, \max },\{t \in \mathcal{T}, j \in \mathcal{N}\}, \\
& \operatorname{soc}_{j}^{b, \min } \leq \operatorname{soc}_{j, t}^{b} \leq \operatorname{soc}_{j}^{b, \max },\{t \in \mathcal{T}, j \in \mathcal{N}\}, \\
& p_{j, t}^{g d, \min } \leq p_{j, t}^{g d} \leq p_{j, t}^{g d, \max },\{t \in \mathcal{T}, j \in \mathcal{N}\}, \\
& \left\|\begin{array}{c}
p_{j, t}^{g d} \\
q_{j, t}^{g d}
\end{array}\right\| \leq s_{j}^{g d, \max },\{t \in \mathcal{T}, j \in \mathcal{N}\}, \\
& \left(V^{\min }\right)^{2} \leq u_{j, t} \leq\left(V^{\max }\right)^{2},\{t \in \mathcal{T}, j \in \mathcal{N}\},
\end{aligned}
$$

The mathematical model (17) can be solved using the interior-point or logarithmic barrier method, which, according to [31,36], guarantees that the global optimum is found thanks to the convex structure of the entire mathematical model.

To ensure that the initial and final states of the batteries reach reference values, the following battery life constraints are added to the mathematical model (17):

$$
\begin{aligned}
& \operatorname{soc}_{j, t=t_{i}}^{b}=\operatorname{soc}_{j}^{b, \text { initial }},\left\{t_{i} \in \mathcal{T}, j \in \mathcal{N}\right\}, \\
& \operatorname{soc}_{j, t=t_{f}}^{b}=\operatorname{soc}_{j}^{b, \text { final }},\left\{t_{f} \in \mathcal{T}, j \in \mathcal{N}\right\},
\end{aligned}
$$

where $t_{i}$ and $t_{f}$ are the start and end times of the study period, and $s o c_{j}^{b, \text { initial }}$ and $s o c_{j}^{b, \text { final }}$ represent the initial and final state of charge of the battery $b$ connected to the node $j$. In this study, these values are assumed to be $50 \%$, as recommended in [8].

To classify and characterize the convex optimization model (17), we present a complete classification table where the number of variables and their nature and the type and number of constraints, including the objective function and its components, are listed. Note that $n$ (number of nodes) is defined as the cardinality of the set $\mathcal{N}$, and $p$ (number of periods) the cardinality of the set $\mathcal{T}$.

Note that the model classification listed in Table 1 confirms the conic nature of the optimization model given by the power definition at each line and the power outputs in 
batteries and dispersed sources. In addition, the nature of the decision variables shows that all of those in the studied model are defined in the real domain.

Table 1. Number of variables and constraints in the optimization model (17).

\begin{tabular}{lcc}
\hline Variables & Type & Number \\
\hline Active powers & Real & $(3 n-1) p$ \\
Reactive powers & Real & $(3 n-1) p$ \\
Square voltages & Real & $n p$ \\
Square currents & Real & $(n-1) p$ \\
Batteries' states of charge & Real & $n p$ \\
Objective function & Real & 2 \\
\hline Total variables & Real & $3(3 n-1) p+2$ \\
\hline Constraints & Type & Number \\
\hline Active power balance & Equality (affine) & $n p$ \\
Reactive power balance & Equality (affine) & $n p$ \\
Voltage drops & Equality (affine) \\
Powers from Tellegen's theorem & Inequality conic constraint & $(n-1) p$ \\
Batteries' state of charge behavior & Equality (affine) & $n p$ \\
Apparent power in batteries & Inequality conic constraint & $n p$ \\
Active power cap. in generators and batteries & Inequalities (box-type constraints) & $2 n p$ \\
Batteries' state of charge bounds & Inequality (box-type constraint) & $n p$ \\
Apparent power in disperse generators & Inequality conic constraint & $n p$ \\
Voltage regulation bounds & Inequality (box-type constraint) & $n p$ \\
Initial and final state of charges & Equality (affine) & $2 n$ \\
Objective functions & Equality (affine) & 2 \\
\hline Total constraints & Equalities + Inequalities & $(11 n-2) p+2(n+1)$ \\
\hline
\end{tabular}

\section{Solution Strategy}

Due to the fact that this is a multi-objective mathematical model (17) and that convex optimization methods are applicable to single-objective models, in this study, the weighted weights method is used to derive a single objective function [37] in which the weights are varied in order to obtain the Pareto optimal front. The equivalent objective function (i.e., $f_{e}$ ) takes the following form:

$$
\min f_{e}=\omega \frac{f_{1}}{F_{1}^{\max }}+(1-\omega) \frac{f_{2}}{F_{2}^{\max }},
$$

where $\omega$ is the weight factor, associated with each objective function, which ranges from 0 to 1 . If $\omega=1$, the global minimum is determined for the objective function associated with greenhouse gas emissions $\left(F_{1}^{\max }\right)$, and if $\omega=0$, the global optimum will be found for the cost of energy losses during the study period $\left(F_{2}^{\max }\right)$. The Pareto optimal front is found by starting with $\omega=0$ and increasing its value in 0.05 increments until reaching $\omega=1$ using an iterative process in which the global optimum of the combined problem is found for each value of $\omega$ between 0 and 1. Equation (18) was normalized to combine the two objective functions because they have different units. In addition, in this article, the mathematical model (17) is solved using the CVX optimization package in the MATLAB 2020b programming environment and the SeDuMi and SDPT3 solvers [38].

\section{Test System and Characteristics}

To evaluate the optimal battery operation method in distribution systems presented in (17), the IEEE 33-node radial distribution system [11] is considered as the test system, which is operated at medium-voltage levels, with a voltage of $12.66 \mathrm{kV}$ at the slack node (bar 1). The structure of this test system is shown in Figure 1. The total active and reactive 
power consumption at the peak hour of this system is $3715 \mathrm{~kW}$ and $2300 \mathrm{kvar}$, respectively. The data associated with the reactances and resistances of the lines in this test system are available from [11].

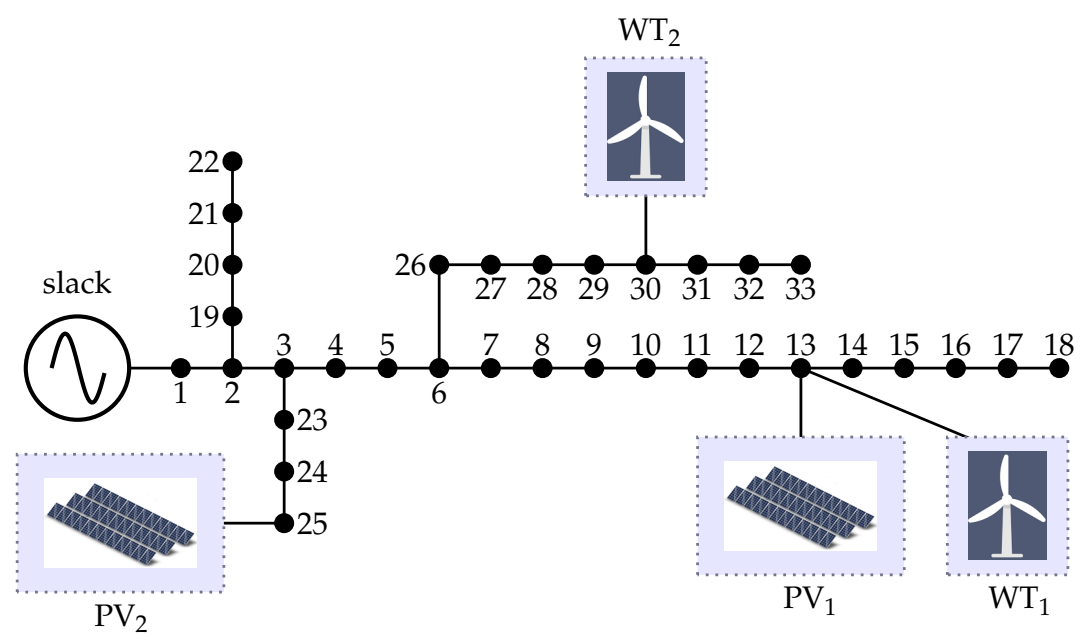

Figure 1. IEEE 33-node system with renewable generation.

The data of the daily demand curves and solar and wind generation profiles are outlined in Table 2 and were retrieved from [8]. The renewable generation sources have the following peak values retrieved from [24].

$\checkmark \quad$ The photovoltaic generator $\mathrm{PV}_{1}$ is connected to node 13 with a nominal generation of $450 \mathrm{~kW}$, and the photovoltaic generator $\mathrm{PV}_{2}$ is installed at node 25 with a nominal generation of $1500 \mathrm{~kW}$;

$\checkmark \quad$ The wind generator $\mathrm{WT}_{1}$ is installed at node 13 with a nominal power of $825 \mathrm{~kW}$, and the wind generator $\mathrm{WT}_{2}$ is installed at node 30 with a maximum power generation of $1200 \mathrm{~kW}$.

The IEEE 33-node system relies on three lithium-ion batteries installed, whose characteristics are listed below [39]:

$\checkmark \quad$ A type-A battery with an energy storage capacity of $1000 \mathrm{kWh}$ and charge/discharge times of $4 \mathrm{~h}$;

$\checkmark \quad$ A type-B battery with an energy storage capacity of $1500 \mathrm{kWh}$ and charge/discharge times of $4 \mathrm{~h}$;

$\checkmark \quad$ A type-C battery with an energy storage capacity of $2000 \mathrm{kWh}$ and charge/discharge times of $5 \mathrm{~h}$.

According to [11], the type-A battery is installed at node 14, the type-B battery at node 31 , and the type-C battery at node 6 , respectively. It is important to note that, in order to preserve the useful life of these batteries, their states of charge must be maintained within a range of $10 \%$ to $90 \%$, based on experimental data reported in [40].

To quantify the effects of the variation in demand and alternative energies in energy storage systems, the average rate of $\mathrm{CO}_{2}$ emitted to the atmosphere by a diesel generation source is set at $612.35 \mathrm{~kg} / \mathrm{MWh}$ and the energy cost in USD $/ \mathrm{kWh}$ is set at 0.1390 . These data have been set considering an average emission of $1350 \mathrm{lb} / \mathrm{MWh}$ and an average energy cost in Colombia for May 2019 of COP/kWh of 479.3389 [8]. 
Table 2. Solar and wind generation data for each time period.

\begin{tabular}{|c|c|c|c|c|c|}
\hline Per. (h) & $\mathrm{PV}_{1}(\mathrm{pu})$ & $\mathrm{PV}_{2}(\mathrm{pu})$ & $\mathrm{WT}_{1}(\mathrm{pu})$ & $\mathrm{WT}_{2}(\mathrm{pu})$ & Dem. (pu) \\
\hline 1 & 0 & 0 & 0.6303 & 0.4854 & 0.4854 \\
\hline 2 & 0 & 0 & 0.6194 & 0.4632 & 0.4632 \\
\hline 3 & 0 & 0 & 0.6098 & 0.4452 & 0.4452 \\
\hline 4 & 0 & 0 & 0.6050 & 0.4369 & 0.4369 \\
\hline 5 & 0 & 0 & 0.6122 & 0.4341 & 0.4341 \\
\hline 6 & 0 & 0 & 0.6411 & 0.4383 & 0.4383 \\
\hline 7 & 0 & 0 & 0.6927 & 0.4438 & 0.4438 \\
\hline 8 & 0 & 0 & 0.7395 & 0.4535 & 0.4535 \\
\hline 9 & 0 & 0 & 0.7779 & 0.4646 & 0.4646 \\
\hline 10 & 0 & 0 & 0.7887 & 0.4799 & 0.4799 \\
\hline 11 & 0 & 0 & 0.7671 & 0.5007 & 0.5007 \\
\hline 12 & 0 & 0 & 0.7479 & 0.5381 & 0.5381 \\
\hline 13 & 0 & 0 & 0.7287 & 0.5936 & 0.5936 \\
\hline 14 & 0 & 0 & 0.7371 & 0.6491 & 0.6491 \\
\hline 15 & 0 & 0 & 0.7731 & 0.7115 & 0.7115 \\
\hline 16 & 0.0016 & 0.0238 & 0.8031 & 0.7698 & 0.7698 \\
\hline 17 & 0.0403 & 0.1244 & 0.8271 & 0.8225 & 0.8225 \\
\hline 18 & 0.1344 & 0.2715 & 0.8523 & 0.8558 & 0.8558 \\
\hline 19 & 0.2710 & 0.4394 & 0.8788 & 0.8682 & 0.8682 \\
\hline 20 & 0.3673 & 0.6037 & 0.9064 & 0.8793 & 0.8793 \\
\hline 21 & 0.4584 & 0.7325 & 0.9328 & 0.8890 & 0.8890 \\
\hline 22 & 0.6125 & 0.8096 & 0.9520 & 0.9001 & 0.9001 \\
\hline 23 & 0.8134 & 0.8603 & 0.9640 & 0.9112 & 0.9112 \\
\hline 24 & 0.9122 & 0.9838 & 0.9700 & 0.9251 & 0.9251 \\
\hline 25 & 0.9633 & 1.0000 & 0.9748 & 0.9376 & 0.9376 \\
\hline 26 & 1.0000 & 0.9754 & 0.9784 & 0.9501 & 0.9501 \\
\hline 27 & 0.9582 & 0.7709 & 0.9832 & 0.9626 & 0.9626 \\
\hline 28 & 0.8791 & 0.8888 & 0.9880 & 0.9750 & 0.9750 \\
\hline 29 & 0.7308 & 0.6296 & 0.9940 & 0.9861 & 0.9861 \\
\hline 30 & 0.7645 & 0.5932 & 0.9988 & 0.9945 & 0.9945 \\
\hline 31 & 0.6866 & 0.4043 & 1.0000 & 0.9986 & 0.9986 \\
\hline 32 & 0.5893 & 0.3659 & 0.9964 & 1.0000 & 1.0000 \\
\hline 33 & 0.4193 & 0.2307 & 0.9892 & 0.9986 & 0.9986 \\
\hline 34 & 0.2784 & 0.2025 & 0.9652 & 0.9931 & 0.9931 \\
\hline 35 & 0.1373 & 0.1299 & 0.9244 & 0.9847 & 0.9847 \\
\hline 36 & 0.0374 & 0.0532 & 0.8607 & 0.9626 & 0.9626 \\
\hline 37 & 0.0007 & 0.0084 & 0.7743 & 0.9293 & 0.9293 \\
\hline 38 & 0 & 0 & 0.7251 & 0.8613 & 0.8613 \\
\hline 39 & 0 & 0 & 0.7167 & 0.7587 & 0.7587 \\
\hline 40 & 0 & 0 & 0.7167 & 0.7004 & 0.7004 \\
\hline 41 & 0 & 0 & 0.7251 & 0.6865 & 0.6865 \\
\hline 42 & 0 & 0 & 0.7263 & 0.6865 & 0.6865 \\
\hline 43 & 0 & 0 & 0.7179 & 0.7018 & 0.7018 \\
\hline 44 & 0 & 0 & 0.7095 & 0.7143 & 0.7143 \\
\hline 45 & 0 & 0 & 0.6987 & 0.7226 & 0.7226 \\
\hline 46 & 0 & 0 & 0.6915 & 0.7295 & 0.7295 \\
\hline 47 & 0 & 0 & 0.6867 & 0.7351 & 0.7351 \\
\hline 48 & 0 & 0 & 0.6831 & 0.7379 & 0.7379 \\
\hline
\end{tabular}

\section{Computational Validation and Discussion}

In this section, the computational validation of the proposed method for the economicenvironmental dispatch of energy storage systems in AC distribution networks is presented using a convex multi-objective programming model (see mathematical formulation (17)). 
The solution of this mathematical model is implemented on a personal computer MD Ryzen 7 3700U (AMD, Santa Clara, CA, USA), 2.3 GHz, 16 GB RAM with 64-bits Windows 10 Home Single Language using the software MATLAB 2020b, CVX convex optimization package, and SeDuMi and SDPT3 solvers.

The CVX package is a mathematical modeling tool compatible with MATLAB software for solving convex optimization problems, making it possible to write objective functions and constraints using the general syntax of MATLAB software. For further details, please refer to [41].

To operate the batteries in the IEEE 33-node test system, two test scenarios are considered: scenario 1 (i.e., $\mathbf{E}_{1}$ ), which considers the operation of the batteries with a power factor of 1.0, and scenario 2 (i.e., $\mathbf{E}_{2}$ ), which considers the reactive power injection. In a distributed generation, in both scenarios, the batteries operate with a unity power factor. The batteries start and end the daily operating periods charged to $50 \%$, as recommended in [22].

\subsection{Scenario 1}

Figure 2 shows the Pareto front associated with the BESS operating with a power factor of 1.0.

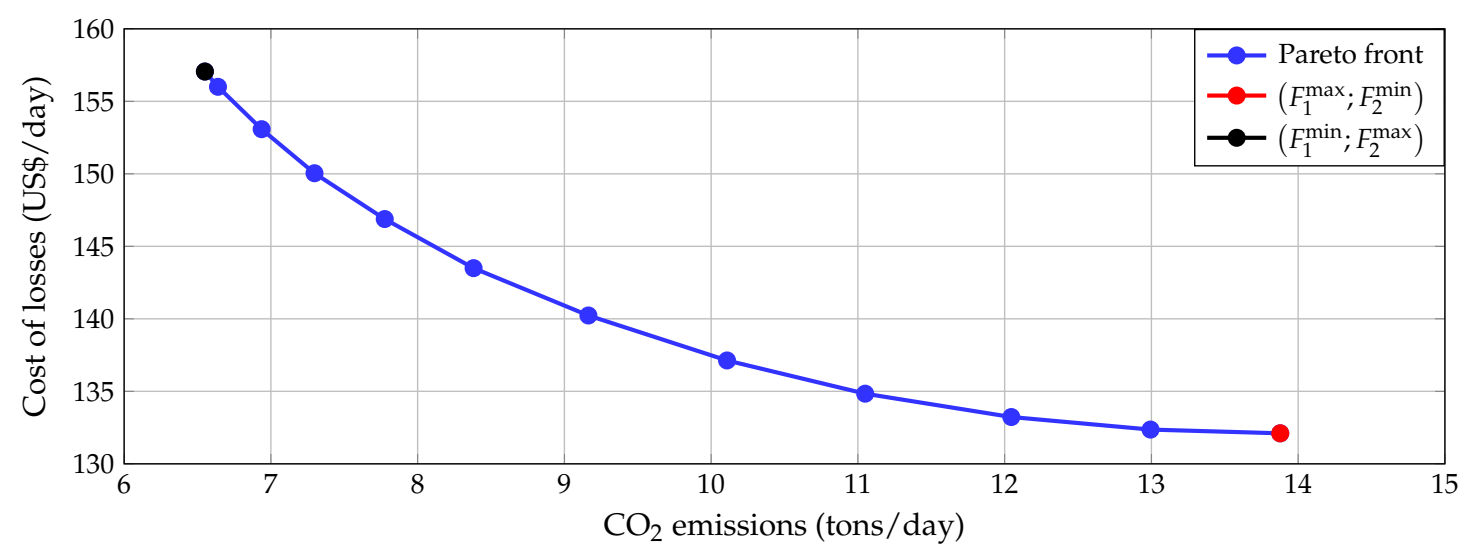

Figure 2. Pareto front for the BESS operation with a unity power factor.

The results shown in Figure 2 indicate that:

$\checkmark$ The maximum value of $\mathrm{CO}_{2}$ gas emissions to the atmosphere, i.e., $F_{1}^{\max }$, is 13.8780 tons/day; whereas the maximum value of the daily cost of energy losses, i.e., $F_{2}^{\max }$, is USD 157.0549;

$\checkmark$ The minimum values of $\mathrm{CO}_{2}$ gas emissions to the atmosphere, i.e., $F_{1}^{\min }$, is 6.5502 tons/day; whereas the minimum value of the daily cost of energy losses, i.e., $F_{2}^{\min }$, is USD 132.1042;

$\checkmark \quad$ The difference between the maximum and minimum values of $\mathrm{CO}_{2}$ gas emissions is 7.3278 tons/day, which implies a maximum achievable reduction of $52.80 \%$;

$\checkmark \quad$ The analysis of the extremes of the daily cost of energy losses shows that the difference between its maximum and minimum values is USD 24.9507, which implies a maximum achievable reduction of $15.89 \%$.

Table 3 presents the values of the objective function for each point represented in the Pareto front of Figure 2.

All solutions presented in Table 3 are optimal because each solution is better than the following in at least one of the two objective functions; that is, the selection of the combination applicable to the distribution system is purely technical and depends solely on the network operator. Nevertheless, the set of solutions 5 to 9 (center of the Pareto front of Figure 2) show an adequate balance between optimizing $\mathrm{CO}_{2}$ emissions and reducing the daily operating costs. Solution no. 5 reduces emissions by $27.16 \%$ and daily operating 
costs by $12.69 \%$, relative to their maximum values. Solution no. 9 reduces $\mathrm{CO}_{2}$ emissions by $47.42 \%$ and daily operating costs associated with energy losses by $4.47 \%$.

Table 3. List of solutions of the Pareto front of Figure 2.

\begin{tabular}{cccccc}
\hline No. & $f_{\mathbf{1}}$ (tons/day) & $f_{\mathbf{2}}$ (USD/day) & No. & $f_{\mathbf{1}}$ (tons/day) & $f_{\mathbf{2}}$ (USD/day) \\
\hline 1 & 13.8780 & 132.1042 & 7 & 8.3812 & 143.4954 \\
2 & 12.9941 & 132.3619 & 8 & 7.7757 & 146.8818 \\
3 & 12.0455 & 133.2272 & 9 & 7.2971 & 150.0405 \\
4 & 11.0497 & 134.8376 & 10 & 6.9370 & 153.0781 \\
5 & 10.1083 & 137.1284 & 11 & 6.6395 & 156.0007 \\
6 & 9.1637 & 140.2305 & 12 & 6.5502 & 157.0549 \\
\hline
\end{tabular}

\subsection{Scenario 2}

In this scenario, the effect of the reactive power injections of the batteries on the Pareto optimal front is evaluated. Figure 3 shows this Pareto front.

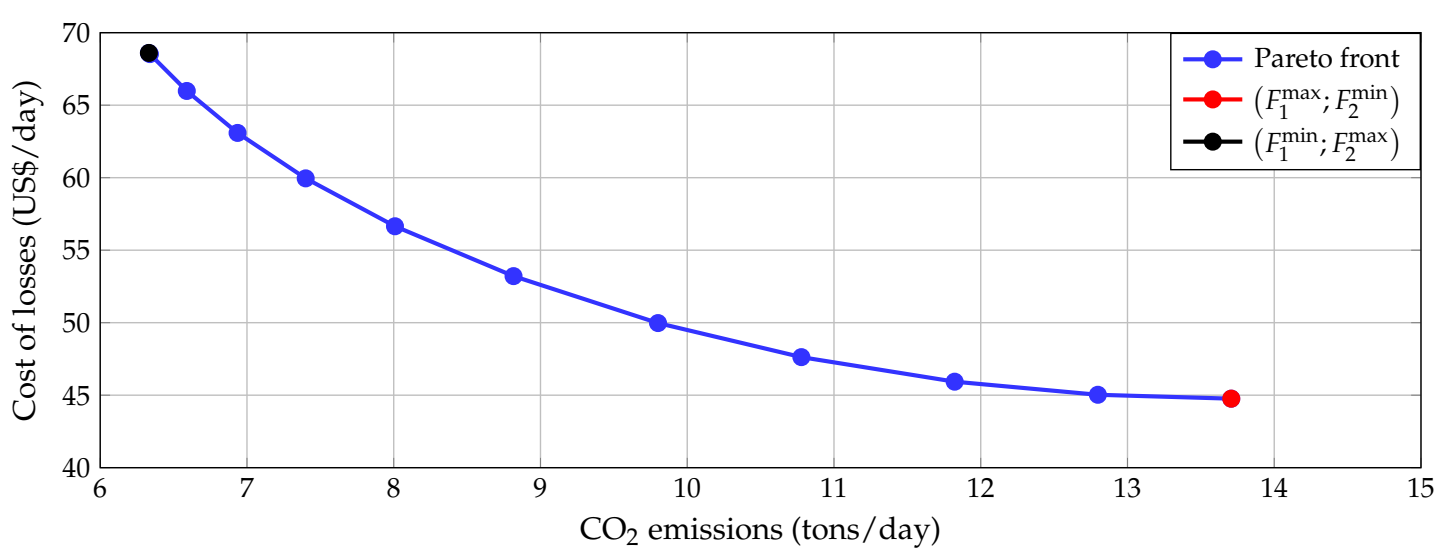

Figure 3. Pareto front for the BESS operation with variable power factor.

The results presented in the Pareto front of Figure 3 show that:

$\checkmark \quad$ The maximum value of $\mathrm{CO}_{2}$ gas emissions to the atmosphere, i.e., $F_{1}^{\max }$, is 13.7072 tons/day, whereas the maximum value of the daily cost of energy losses, i.e., $F_{2}^{\max }$, is USD 68.6022. These results imply a reduction of 0.1708 tons/day in greenhouse gas emissions and 85.4527 USD/day in the cost of energy losses;

$\checkmark \quad$ The minimum value of $\mathrm{CO}_{2}$ gas emissions to the atmosphere, i.e., $F_{1}^{\min }$, is 6.3317 tons/day, whereas the minimum value of the daily cost of energy losses, i.e., $F_{2}^{\mathrm{min}}$, is USD 44.7601. As in the case of the upper bounds, in this case, daily reductions of 0.2185 tons of $\mathrm{CO}_{2}$ and USD 87.3441 are achieved;

$\checkmark \quad$ The main effect of reactive power injection on the multi-objective operation of the BESS is to reduce energy losses in conductors, because this reduction helps to locally offset the consumption of reactants, which translates into currents of lower magnitude in the branches, and, therefore, lower losses.

Table 4 presents the values of the objective functions for each point represented in the Pareto front of Figure 3.

The comparison of the solutions reported in Tables 3 and 4 shows that the average reduction in greenhouse gas emissions is 0.2910 tons/day, i.e., over $200 \mathrm{~kg}$ of $\mathrm{CO}_{2}$ per day, and that the reduction of the operational costs of power losses is, on average, USD 87.2598 per day of operation. These results clearly demonstrate the positive effects of reactive power injection through the battery converter, as reported in [8]. 
Table 4. List of solutions of the Pareto front of Figure 3.

\begin{tabular}{cccccc}
\hline No. & $f_{\mathbf{1}}$ (tons/day) & $f_{\mathbf{2}}$ (USD/day) & No. & $f_{\mathbf{1}}$ (tons/day) & $f_{\mathbf{2}}$ (USD/day) \\
\hline 1 & 13.7072 & 44.7601 & 7 & 8.0085 & 56.6499 \\
2 & 12.7983 & 45.0283 & 8 & 7.4001 & 59.9527 \\
3 & 11.8224 & 45.9312 & 9 & 6.9359 & 63.0869 \\
4 & 10.7779 & 47.6243 & 10 & 6.5899 & 65.9802 \\
5 & 9.8010 & 49.9735 & 11 & 6.3386 & 68.5226 \\
6 & 8.8164 & 53.2112 & 12 & 6.3317 & 68.6023 \\
\hline
\end{tabular}

\subsection{Complementary Analysis}

The performance of BESS during one possible operating scenario was illustrated by assuming that the network operator selected solution no. 7, listed in Table 4, whose results associated with the battery variables are shown in Figure 4.
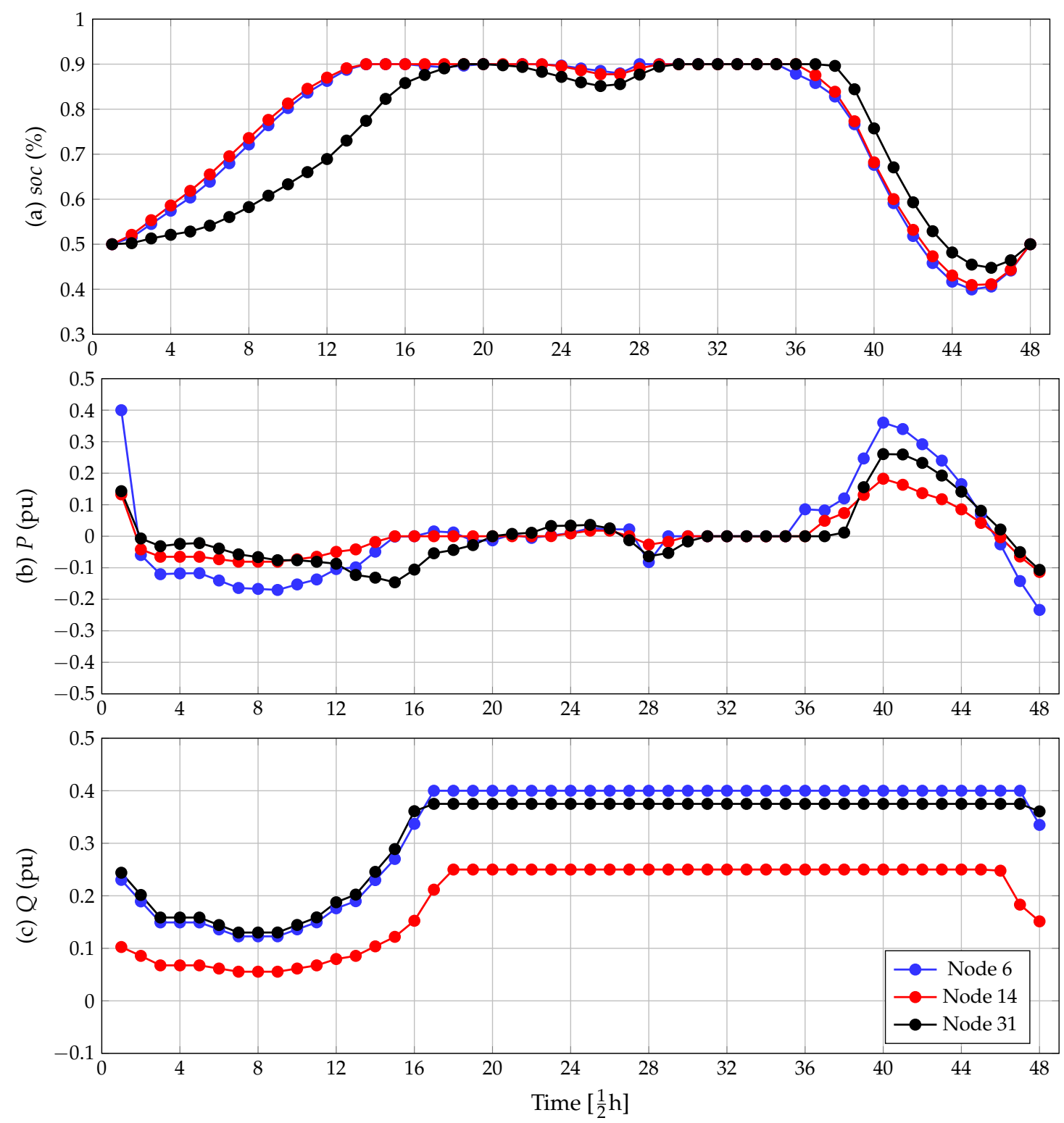

Figure 4. Behavior of BESS variables in solution no. 7 of Table 4: (a) states of charge, (b) active power, and (c) reactive power. 
The results displayed in Figure 4 show that:

$\checkmark \quad$ The batteries are charged during the earlier time periods between 6 a.m. and 10 a.m. (see Figure $4 \mathrm{a}$ ), periods during which the active power of the battery is negative (see Figure $4 \mathrm{~b}$ ), because this energy is being used to increase the state of charge from $50 \%$ to $90 \%$, which corresponds to the upper bound established for this state of charge;

$\checkmark \quad$ Between 10 a.m. to 6 p.m., the state of charge of the batteries remains stable, with only small variations, which implies that the injected (absorbed) active power is practically nil in this entire operating range;

$\checkmark \quad$ After 6 p.m., the batteries start discharging the stored energy to the grid, which coincides with a constant decrease in the state of charge until 10 p.m., after which, its state of charge starts to increase again until reaching the final condition of a $50 \%$ state of charge, which was set as an operational target. When the state of charge decreases, the active power is positive, which implies a power flow from the battery to the electrical grid (compare Figure $4 \mathrm{a}, \mathrm{b}$ );

$\checkmark \quad$ The behavior of the reactive power shown in Figure 4c demonstrates that this variable is independent of the state of charge (see the mathematical model (17)) and that it only depends on the ability of the converter to transfer/absorb power. Accordingly, the battery always delivers reactive power to the grid, and delivers the maximum possible reactive power in the period from 8 a.m. to 11 p.m.

The above variations demonstrate that batteries substantially reduce the cost of energy losses while mitigating greenhouse gas emissions when considering their apparent power injection capabilities because they can perform as dynamic active and reactive power compensators with a range of maneuvers in all four quadrants. This variable performance of the injected reactive power is achieved using control methods (see [21]), enabling better solutions than those achieved when placing a variable pitch capacitor without investing in additional devices.

Figure 5 shows the variation of the states of charge of the three batteries when considering the two extremes of the Pareto front in the case of the unity power factor; that is, the minimization of daily energy losses and greenhouse gas emissions (see points in Figure 2).

The behavior of the states of charge of the batteries located in nodes 6,14 , and 31 in this comparative scenario shows that the main difference between both extreme operating scenarios is identified between periods 16 and 28 for the three batteries because the state of charge is higher when minimizing losses than when minimizing $\mathrm{CO}_{2}$ emissions. This variation occurs because, during this period, the energy demand markedly increases, which should be partly met by the conventional source. This implies that conventional generation will be lower if the batteries are discharged in this period (batteries injecting active power). Therefore, atmospheric gas emissions will decrease, thus fulfilling the objective of minimizing emissions. In all scenarios analyzed in this study, the batteries always met their operating margins. In other words, the solution will always be feasible.

It is important to mention that the uncertainties of the primary resources, such as wind speed and solar radiation for renewable energy, can be a factor that is essential in the performance of the proposed multi-objective problem performed in this paper. However, using an adequate methodology, this problem can be resolved as presented in [42]. The authors of [42] proposed a mix between a receding horizon control and nonlinear autoregressive exogenous model (NARX) to reduce the forecasting errors of the primary resources. This mix consists of using the NARX to predict the wind speed and solar radiation by $n$-periods and performing the economic dispatch in the $n+1$ period, then recalculating the predictions of wind speed and solar radiation with information of the $n+1$ period.

For implementing the proposed conic model, it is essential to note that two main considerations were made: (i) all of the renewable generation and demand profiles are considered as exogenous inputs in the proposed conic model, which implies that the accuracy between the projected daily operation and the real daily operation results will depend only on the quality of those data; and (ii) the daily battery profiles are sent to 
the physical location of the batteries using available communication channels, since the proposed optimization methodology corresponds, in other words, to a tertiary controller, which was designed considering a centralized structure.
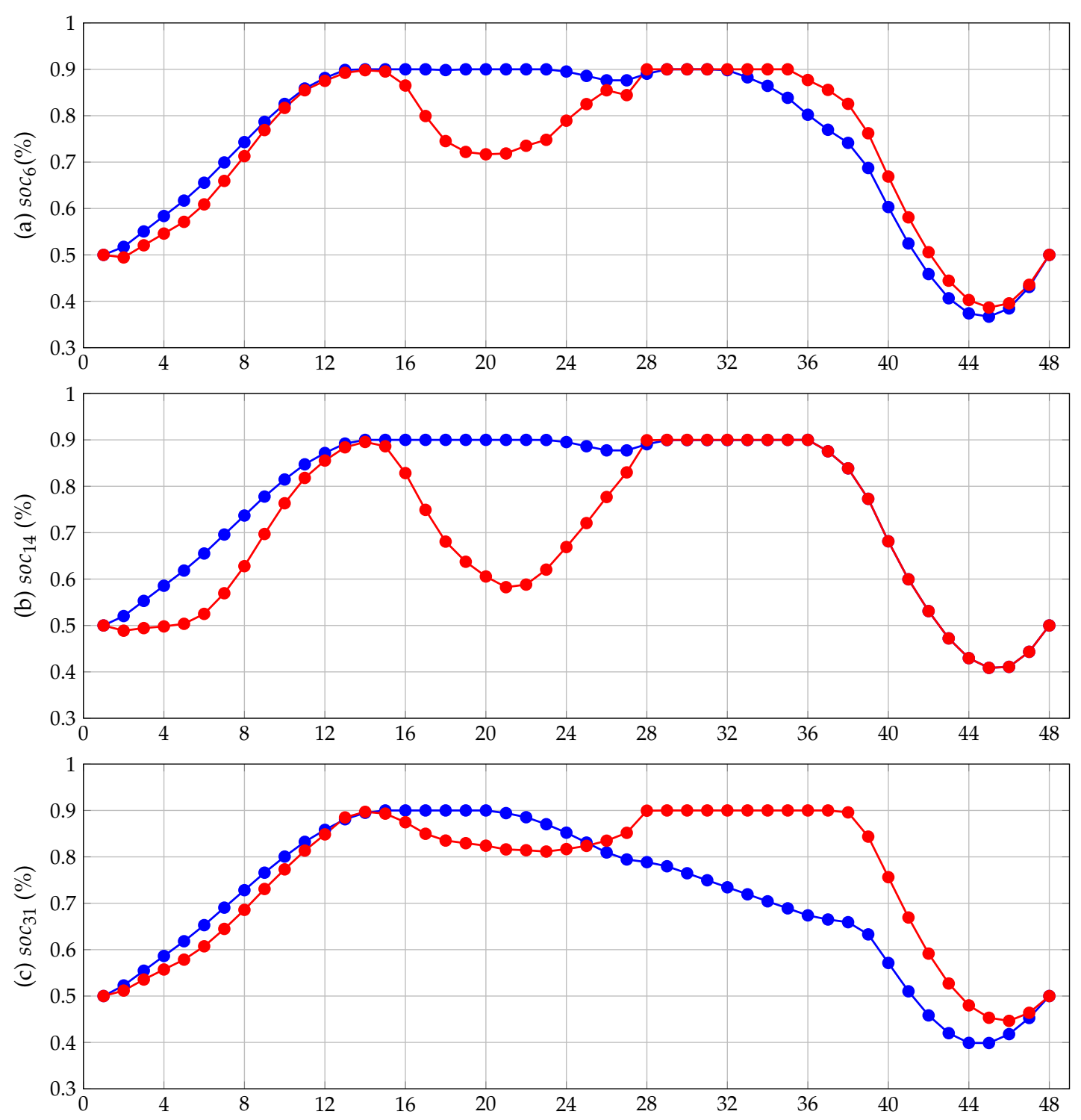

Figure 5. Behavior in the states of charge with the unity power factor simulation case.

\section{Conclusions and Future Work}

In this article, a multi-objective formulation was presented for the problem of optimal battery operation in radial alternating current distribution systems by reformulating a second-order cone programming model to transform the original non-linear problem into a convex equivalent, thereby ensuring that the optimal Pareto front was obtained. For this purpose, the weighted weights method was applied to combine both objective functions so that the multi-objective problem (greenhouse gases vs. cost of energy losses) was solved through an equivalent single-objective programming model. The main advantage of this SOCP formulation is that, through the convex optimization theory, the global optimum is always found using the interior-point or logarithmic barrier method, which only requires transforming the multi-period optimal power flow problem into an equivalent cone programming model by relaxing the hyperbolic relationship between the voltages and the powers in each of the network branches. 
Including the dispatch of the reactive power available in the battery's conversion system, on average, $\mathrm{CO}_{2}$ emissions are reduced by $200 \mathrm{~kg}$ and the system's operating cost is reduced by more than USD 80 per day of operation, when compared to the unity power factor operating scenario. These results confirmed the benefits of analyzing battery banks as dynamic apparent power compensation banks, which, by taking advantage of electronic power converters, guarantee significant reductions in current flows through the branches, which results in significant environmental and economic benefits, without the need for additional investments.

Based on this article, the following studies can be proposed: (i) to reformulate the proposed SOCP model by including binary variables associated with the optimal location of the batteries, which would generate an MI-SOCP model that can be solved using branching and probing methods combined with interior points, thereby guaranteeing that the global optimum is found; and (ii) to include constraints associated with the useful life of the batteries, energy losses in converters that interface them, and uncertainties of the demand and renewable generation in the optimization model, thus guaranteeing their convex structure for the optimal global solution with the SEDUMI and SDPT3 solvers available for the MATLAB CVX tool.

Author Contributions: Conceptualization, W.G.-G. and O.D.M.; methodology, W.G.-G. and O.D.M.; investigation, W.G.-G. and O.D.M.; writing-review and editing, W.G.-G., O.D.M., L.F.G.-N. and A.E.-M. All authors have read and agreed to the published version of the manuscript.

Funding: The authors want to thank Vicerrectoria de Investigación, Innovación y Extensión from Universidad Tecnológica de Pereira for the support provided in this investigation. The authors also want to thank Undergraduate and Master's Degree in Electrical Engineering from Universidad Tecnológica de Pereira.

Institutional Review Board Statement: Not applicable.

Informed Consent Statement: Informed consent was obtained from all subjects involved in the study.

Data Availability Statement: Data sharing is not applicable to this article.

Acknowledgments: This research was partially supported by Minciencias, Instituto Tecnológico Metropolitano, Universidad Nacional de Colombia and Universidad del Valle, under the research project "Estrategias de dimensionamiento, planeación y gestión inteligente de energía a partir de la integración y la optimización de las fuentes no convencionales, los sistemas de almacenamiento y cargas eléctricas, que permitan la generación de soluciones energéticas confiables para los territorios urbanos y rurales de Colombia", which belongs to the research program "Estrategias para el desarrollo de sistemas energéticos sostenibles, confiables, eficientes y accesibles para el futuro de Colombia.

Conflicts of Interest: The authors declare no conflict of interest.

\section{Abbreviations}

The following abbreviations are used in this manuscript:

$f_{1} \quad$ Objective function that quantifies the amount of $\mathrm{CO}_{2}$ emissions to the atmosphere (tons/day).

$f_{2} \quad$ Objective function that quantifies the daily cost of energy losses (USD/day).

$\mathrm{CO}_{2}^{\mathrm{em}} \quad$ Carbon dioxide emission rate for medium-capacity diesel generation $(\mathrm{kg} / \mathrm{MWh})$.

$C_{\text {ave }}^{\text {energy }}$ Average cost of electricity (USD/Wh).

$p_{0 i, t} \quad$ Active power flowing from the substation node (i.e., source node 0 ) to the node $i$ in the time period $t$ (MW).

$R_{i j} \quad$ Resistance of the network branch between the nodes $i$ and $j(\Omega)$.

$R_{i j} \quad$ Reactance of the network branch between the nodes $i$ and $j(\Omega)$.

$I_{i j, t} \quad$ Magnitude of the current flowing between the nodes $i$ and $j$ in the time period $t$ (A). 


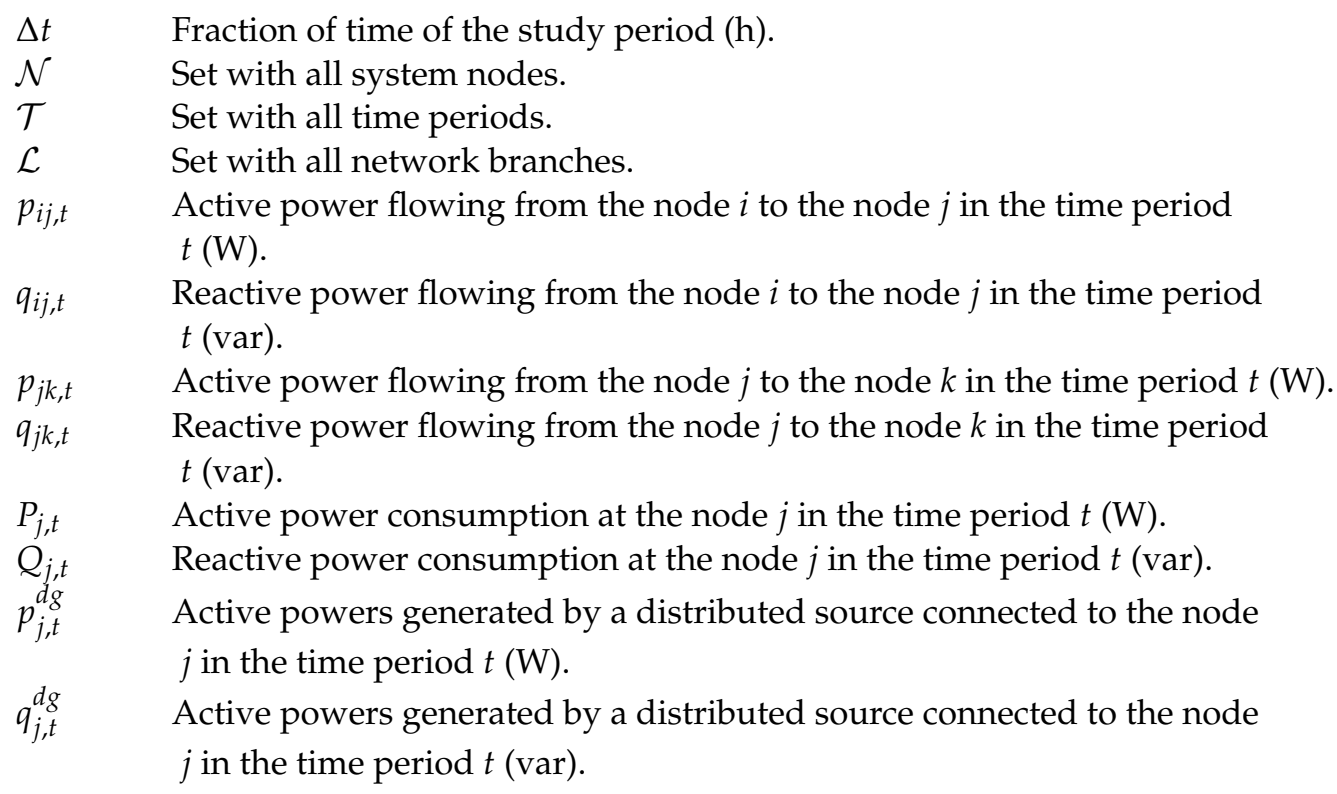

\section{References}

1. Kocer, M.C.; Cengiz, C.; Gezer, M.; Gunes, D.; Cinar, M.A.; Alboyaci, B.; Onen, A. Assessment of Battery Storage Technologies for a Turkish Power Network. Sustainability 2019, 11, 3669. [CrossRef]

2. Zheng, Y.; Zhao, J.; Song, Y.; Luo, F.; Meng, K.; Qiu, J.; Hill, D.J. Optimal Operation of Battery Energy Storage System Considering Distribution System Uncertainty. IEEE Trans. Sustain. Energy 2018, 9, 1051-1060. [CrossRef]

3. Li, B.; Wang, Y.; Li, J.; Cao, S. A Fully Distributed Approach for Economic Dispatch Problem of Smart Grid. Energies 2018, 11, 1993. [CrossRef]

4. Monteiro, R.V.; Guimarães, G.C.; Moura, F.A.; Albertini, M.R.; Silva, F.B. Long-term sizing of lead-acid batteries in order to reduce technical losses on distribution networks: A distributed generation approach. Electr. Power Syst. Res. 2017, 144, 163-174. [CrossRef]

5. Koehler, U. General Overview of Non-Lithium Battery Systems and their Safety Issues. In Electrochemical Power Sources: Fundamentals, Systems, and Applications; Elsevier: Amsterdam, The Netherlands, 2019; pp. 21-46. [CrossRef]

6. Hesse, H.; Schimpe, M.; Kucevic, D.; Jossen, A. Lithium-Ion Battery Storage for the Grid-A Review of Stationary Battery Storage System Design Tailored for Applications in Modern Power Grids. Energies 2017, 10, 2107. [CrossRef]

7. Chen, T.; Jin, Y.; Lv, H.; Yang, A.; Liu, M.; Chen, B.; Xie, Y.; Chen, Q. Applications of Lithium-Ion Batteries in Grid-Scale Energy Storage Systems. Trans. Tianjin Univ. 2020, 26, 208-217. [CrossRef]

8. Montoya, O.D.; Gil-González, W. Dynamic active and reactive power compensation in distribution networks with batteries: A day-ahead economic dispatch approach. Comput. Electr. Eng. 2020, 85, 106710. [CrossRef]

9. Zhu, Y.; Liu, C.; Wang, B.; Sun, K. Damping control for a target oscillation mode using battery energy storage. J. Mod. Power Syst. Clean Energy 2018, 6, 833-845. [CrossRef]

10. Bangash, K.N.; Farrag, M.E.A.; Osman, A.H. Investigation of Energy Storage Batteries in Stability Enforcement of Low Inertia Active Distribution Network. Technol. Econ. Smart Grids Sustain. Energy 2019, 4, 1. [CrossRef]

11. Montoya, O.D.; Gil-González, W.; Hernández, J.C. Optimal Selection and Location of BESS Systems in Medium-Voltage Rural Distribution Networks for Minimizing Greenhouse Gas Emissions. Electronics 2020, 9, 2097. [CrossRef]

12. Li, X.; Wang, S. A review on energy management, operation control and application methods for grid battery energy storage systems. CSEE J. Power Energy Syst. 2019. [CrossRef]

13. Vargas, A.; Samper, M.E. Real-Time Monitoring and Economic Dispatch of Smart Distribution Grids: High Performance Algorithms for DMS Applications. IEEE Trans. Smart Grid 2012, 3, 866-877. [CrossRef]

14. Zhang, H.; Zhao, D.; Gu, C.; Li, F.; Wang, B. Economic optimization of smart distribution networks considering real-time pricing. J. Mod. Power Syst. Clean Energy 2014, 2, 350-356. [CrossRef]

15. Zhang, R.; Hredzak, B. Nonlinear Sliding Mode and Distributed Control of Battery Energy Storage and Photovoltaic Systems in AC Microgrids With Communication Delays. IEEE Trans. Ind. Inform. 2019, 15, 5149-5160. [CrossRef]

16. Becherif, M.; Ayad, M.Y.; Henni, A.; Wack, M.; Aboubou, A.; Allag, A.; Sebai, M. Passivity-Based Control and Sliding Mode Control applied to Electric Vehicles based on Fuel Cells, Supercapacitors and Batteries on the DC Link. In Energy Management; InTech: Rijeka, Croatia, 2010. [CrossRef]

17. Montoya, O.D.; Gil-Gonzalez, W.J.; Garces, A.; Escobar-Mejia, A.; Norena, L.F.G. Nonlinear Control for Battery Energy Storage Systems in Power Grids. In Proceedings of the 2018 IEEE Green Technologies Conference (GreenTech), Austin, TX, USA, 4-6 April 2018. [CrossRef] 
18. Swathika, R.; Ram, R.; Kalaichelvi, V.; Karthikeyan, R. Application of fuzzy logic for charging control of lead-acid battery in stand-alone solar photovoltaic system. In Proceedings of the 2013 International Conference on Green Computing, Communication and Conservation of Energy (ICGCE), Chennai, India, 12-14 December 2013. [CrossRef]

19. Jadhav, A.D.; Nair, S. Battery Management using Fuzzy Logic Controller. J. Phys. Conf. Ser. 2019, 1172, 012093. [CrossRef]

20. Lee, H.J.; Jhang, S.S.; Yu, W.K.; Oh, J.H. Artificial Neural Network Control of Battery Energy Storage System to Damp-Out Inter-Area Oscillations in Power Systems. Energies 2019, 12, 3372. [CrossRef]

21. Fernández, L.M.; Serra, F.; Angelo, C.D.; Montoya, O. Control of a charging station for electric vehicles. J. Phys. Conf. Ser. 2020, 1448, 012013. [CrossRef]

22. Montoya, O.D.; Grajales, A.; Garces, A.; Castro, C.A. Distribution Systems Operation Considering Energy Storage Devices and Distributed Generation. IEEE Lat. Am. Trans. 2017, 15, 890-900. [CrossRef]

23. Grisales-Noreña, L.; Montoya, O.D.; Gil-González, W. Integration of energy storage systems in AC distribution networks: Optimal location, selecting, and operation approach based on genetic algorithms. J. Energy Storage 2019, 25, 100891. [CrossRef]

24. Montoya, O.D.; Gil-González, W.; Serra, F.M.; Hernández, J.C.; Molina-Cabrera, A. A Second-Order Cone Programming Reformulation of the Economic Dispatch Problem of BESS for Apparent Power Compensation in AC Distribution Networks. Electronics 2020, 9, 1677. [CrossRef]

25. Zafar, R.; Ravishankar, J.; Fletcher, J.E.; Pota, H.R. Optimal Dispatch of Battery Energy Storage System Using Convex Relaxations in Unbalanced Distribution Grids. IEEE Trans. Ind. Inform. 2020, 16, 97-108. [CrossRef]

26. Abou El-Ela, A.A.; El-Seheimy, R.A.; Shaheen, A.M.; Wahbi, W.A.; Mouwafi, M.T. PV and battery energy storage integration in distribution networks using equilibrium algorithm. J. Energy Storage 2021, 42, 103041. [CrossRef]

27. Shaheen, A.M.; Elattar, E.E.; El-Sehiemy, R.A.; Elsayed, A.M. An Improved Sunflower Optimization Algorithm-Based Monte Carlo Simulation for Efficiency Improvement of Radial Distribution Systems Considering Wind Power Uncertainty. IEEE Access 2021, 9, 2332-2344. [CrossRef]

28. Yuan, Z.; Wang, W.; Wang, H.; Yildizbasi, A. A new methodology for optimal location and sizing of battery energy storage system in distribution networks for loss reduction. J. Energy Storage 2020, 29, 101368. [CrossRef]

29. Deng, T.; Ran, Y.; Yin, Y.; Liu, P. Multi-objective optimization design of thermal management system for lithium-ion battery pack based on Non-dominated Sorting Genetic Algorithm II. Appl. Therm. Eng. 2020, 164, 114394. [CrossRef]

30. Shaheen, A.M.; Hamida, M.A.; El-Sehiemy, R.A.; Elattar, E.E. Optimal parameter identification of linear and non-linear models for Li-Ion Battery Cells. Energy Rep. 2021, 7, 7170-7185. [CrossRef]

31. Farivar, M.; Low, S.H. Branch Flow Model: Relaxations and Convexification-Part I. IEEE Trans. Power Syst. 2013, 28, 2554-2564. [CrossRef]

32. Liu, W.; Zheng, T.; Liu, Z.; Fan, Z.; Kang, Y.; Wang, D.; Zhang, M.; Miao, S. Active and Reactive Power Compensation Control Strategy for VSC-HVDC Systems under Unbalanced Grid Conditions. Energies 2018, 11, 3140. [CrossRef]

33. Gonzalez, W.J.G.; Bocanegra, S.Y.; Serra, F.M.; Bueno-López, M.; Magaldi, G.L. Control Methods for Single-phase Voltage Supply with VSCs to Feed Nonlinear Loads in Rural Areas. Trans. Energy Syst. Eng. Appl. 2020, 1, 33-47. [CrossRef]

34. Montoya, O.D.; Gil-González, W.; Hernández, J.C. Efficient Operative Cost Reduction in Distribution Grids Considering the Optimal Placement and Sizing of D-STATCOMs Using a Discrete-Continuous VSA. Appl. Sci. 2021, 11, 2175. [CrossRef]

35. Serra, F.M.; Fernández, L.M.; Montoya, O.D.; Gil-González, W.; Hernández, J.C. Nonlinear Voltage Control for Three-Phase DC-AC Converters in Hybrid Systems: An Application of the PI-PBC Method. Electronics 2020, 9, 847. [CrossRef]

36. Benson, H.Y.; Sağlam, Ü. Mixed-Integer Second-Order Cone Programming: A Survey. In Theory Driven by Influential Applications; INFORMS: Catonsville, MD, USA, 2013; pp. 13-36. [CrossRef]

37. Chen, G.; Yi, X.; Zhang, Z.; Lei, H. Solving the Multi-Objective Optimal Power Flow Problem Using the Multi-Objective Firefly Algorithm with a Constraints-Prior Pareto-Domination Approach. Energies 2018, 11, 3438. [CrossRef]

38. Eltved, A.; Dahl, J.; Andersen, M.S. On the robustness and scalability of semidefinite relaxation for optimal power flow problems. Optim. Eng. 2019, 21, 375-392. [CrossRef]

39. Molina-Martin, F.; Montoya, O.D.; Grisales-Noreña, L.F.; Hernández, J.C.; Ramírez-Vanegas, C.A. Simultaneous Minimization of Energy Losses and Greenhouse Gas Emissions in AC Distribution Networks Using BESS. Electronics 2021, 10, 1002. [CrossRef]

40. Lipu, M.S.H.; Hannan, M.A.; Hussain, A.; Ayob, A.; Saad, M.H.M.; Muttaqi, K.M. State of Charge Estimation in Lithium-Ion Batteries: A Neural Network Optimization Approach. Electronics 2020, 9, 1546. [CrossRef]

41. Grant, M.; Boyd, S. CVX: Matlab Software for Disciplined Convex Programming, Version 2.1. 2014. Available online: http: / / cvxr.com/cvx (accessed on 3 November 2021).

42. Gil-González, W.; Montoya, O.D.; Holguín, E.; Garces, A.; Grisales-Noreña, L.F. Economic dispatch of energy storage systems in dc microgrids employing a semidefinite programming model. J. Energy Storage 2019, 21, 1-8. [CrossRef] 